\title{
INTERNATIONAL PROTECTION AND PSYCHOSOCIAL SUPPORT SERVICES
}

\author{
Saime Ozcurumez
}

Why is it important to study policies on mental health and psychosocial services (MHPSS) provided to refugees? The answer remains complex and context-bound. Scholars agree on the need for MHPSS in emergency settings, though they disagree on the context and content, as well as methods for delivery (Diaz, 2008; Wessells \& van Ommeren, 2008; Wessells, 2009; Wietse et al., 2012). Studies accentuate a tentative scholarly consensus on emphasising MHPSS that is resilience enhancing, community oriented, culturally sensitive and focused on social cohesion. However, in receiving refugees, states responsible for the delivery of MHPSS do not have, as yet, any straightforward and enforceable national guidelines to meet refugees' mental health and psychosocial needs. Moreover, at the international level, attention to the psychosocial wellbeing of refugees intensified mostly in the late 2000s.

Receiving states also do not have an international framework that obliges them to provide a long-term perspective for designing and implementing refugee policies beyond temporary refuge. All this is expected to change with the process of the New York Declaration for Refugees and Migrants of September 2016, also known as the Comprehensive Refugee Response Framework (CRRF). The CRRF puts forward objectives for "easing the pressures on host countries, enhancing refugee self-reliance, expanding third country solutions and supporting the conditions in the countries of origin for return in safety and dignity" (United Nations, n.d.a, n.p.). The Declaration aims to overcome one significant gap in the refugee regime, by ensuring that states will aim to share responsibility in times of a mass influx of refugees and do so in a coordinated framework. While this represents a timely reinforcement of the principles of the 1951 Convention and a critical "minor miracle" (Türk, 2016) for transforming the international protection regime, there is a long road ahead for the New York Declaration to become effective beyond the present refugee reception and admission practices. The details of 'responsibility sharing' will be outlined with the Global Compact on Refugees (Global Compact 
on Refugees, 2018). Until then, the nation-states are responsible for organising and implementing humanitarian relief efforts. Providing services for the psychosocial wellbeing of all refugees has also depended on the policy choices of the host states. Then again, millions fleeing the Syrian conflict towards the neighbouring countries and beyond led to a turning point in rethinking the international protection regime. Since 2011, most of the refugees from Syria fled to Turkey, Lebanon, Jordan, Iraq and Egypt. In this time period, regional efforts for increasing coordination and the efficiency of the humanitarian response also intensified, among which the 3RP (Regional Refugee \& Resilience Plan) is the most comprehensive. However, in neither of these efforts have psychosocial services been considered essential components of the relief effort to the extent that they could have been. In the 3RP plan, the psychosocial support services are only part of the protection sector (psychosocial wellbeing of children) and the health and nutrition sector (emphasis on an increased access to mental health and psycho-social support services) (3RP Strategic Overview, 2018-2019).

This chapter seeks answers to the question in what ways and to what extent are psychosocial support services provided for traumatised populations as part of the refugee policy response, and what are the reasons behind the uncertainty around the governance and the content of these services? Therefore, this chapter focuses on the case of Syrians under Temporary Protection in Turkey (SuTP) between 2011 and 2018. The reasons for the current state of affairs are twofold. First, the psychosocial wellbeing of those who have escaped a humanitarian crisis has been a less addressed need in the international protection regimes in cases of mass influx. Second, most states view the provision of mental health and psychosocial services as a priority for their own citizens, and hence do not reserve the necessary financial and human resources for times of crisis, nor do they have access to coordinated action from the international community for these emergency situations. Since states (at least until the Global Compact for Refugees is in full force) have to rely mostly on their national resources for addressing the challenges of mass influx as a result of conflict, they are constrained by their existing legal, administrative and institutional framework. An analysis of the organisation and implementation of MHPSS delivery for the SuTP in Turkey reveals findings that could inform responses to challenges and opportunities for other contexts experiencing a mass influx of refugees.

\section{Legal, administrative and institutional framework for receiving Syrians in Turkey}

For decades, Turkey has been receiving those coming from Afghanistan, Iran, Somalia and Ethiopia, seeking international protection. However, due to the 'geographical limitation' that Turkey adopts while applying its commitments in line with the Convention Relating to the Status of Refugees (also called the 1951 Convention) and its additional 1967 Protocol, Turkey had remained aloof from introducing an extensive legislative, administrative and institutional framework for 
the provision of services to those seeking international protection up until 2013. In the absence of a binding international legal commitment, low levels of public visibility of those seeking international protection, and low public awareness about refugees, a dispersed legal and administrative framework shaped the governance of migration and international protection in Turkey. Even when the 450,000 Iraqis arrived in the 1990s, the mass influx was received and coped with as an urgent policy problem, yet temporary in nature.

At that time, aside from the 1994 Regulation (Regulation No. 1994/6169, 1994), there were no major institutional changes introduced to the legal framework for governing international protection. Therefore, Turkey's initial response to receiving Syrians was shaped by the historical experience of a policy problem that had required urgent mobilisation for a situation that resolved relatively quickly. Accordingly, the construction and administration of the temporary accommodation centres and the governing of the relief efforts after 2011 were centralised around the Presidency of Disaster and Emergency Management (AFAD). As years passed, however, Syrians continued to arrive and international intergovernmental agencies and non-governmental organisations became part of the policy terrain. By early 2018, Turkey was hosting around 3.5 million Syrians and others who were seeking international protection, all with different needs and legal status. In 2013, Turkey adopted the Law on Foreigners and International Protection (LFIP) (United Nations, n.d.b), and as of March 2018, the Directorate General for Migration Management (DGMM) took over from AFAD for the governance of the temporary protection centres. In this overall transformation of the legal framework and the governing structure, the approach to MHPSS delivery to SuTP was also transformed. While the MHPSS had been provided by a variety of actors from international, governmental and non-governmental agencies with mostly project-based short-term activities, the Ministry of Health $(\mathrm{MoH})$ and the Ministry of Family and Social Policies (MFSP) assumed an increasingly central role. The MHPSS became part of the core of discussions and policy initiatives for all actors in the shifting policy paradigm from humanitarian assistance to development, as well as from emergency management to comprehensive social integration and social cohesion.

\section{MHPSS and the international protection nexus in Turkey}

Scholars increasingly emphasise that the experience of forced migration is without spatial and temporal boundaries. Most of the time, the duration of stay in the host state is uncertain and depends on whether the receiving state extends refugee status, whether the conflict ends and there is a possibility of (or willingness for) return, or whether there is an option of moving to a third country. Exacerbated by the precariousness of livelihood opportunities, access to basic needs and public services, refugees remain in a prolonged state of anxiety even after they arrive in a safe haven. Such continuous strains on the individuals result in a deterioration of mental health (Hassan et al., 2015; Hassan,Ventevogel, Jefee-Bahloul, Barkil-Oteo, \& Kirmayer, 2016). Receiving states, such as Turkey, 
address these concerns by mobilising their existing legal, administrative, institutional and human resources in responding to humanitarian crisis along with those resources available to their citizens.

The international context for the provision of health services is guided by the global agreement on the Mental Health and Psychosocial Support in Emergency Settings (IASC, 2010). According to the Inter-Agency Standing Committee (IASC) guidelines, social support is a necessity for ensuring psychosocial wellbeing, especially through coordination of different sectors including camp management, education, food security and nutrition, health, protection, shelter, water and sanitation (IASC, 2010,1). The IASC guidelines identify a pyramid of intervention strategies that begin with social considerations in basic services, strengthening community and family supports, focusing on the needs of the individual and culminating in specialised services (IASC, 2010, 3).

Studies on MHPSS and policy guidelines of the late 2000s present MHPSS in humanitarian crisis as a coordinated action that is part of a comprehensive approach to the social cohesion setting created for refugees. MHPSS is to be embedded in a network of social and institutional settings as well as actors. The mobilisation, coordination and action of both governmental and non-governmental actors around MHPSS are key to the governing of human mobility consequences of a humanitarian crisis. Moreover, MHPSS is multisectoral and embedded in employment, shelter, nutrition, basic health needs and education among other needs. Scholars also point to the need to design and implement MHPSS in a culturally competent and culturally safe way by accounting for the diversities and vulnerabilities of the refugee populations. Also, studies point to a need for designing a 'multi-layered MHPSS' that would account for "social consideration in basic services and security, strengthening community and family supports, focused psychosocial support, clinical services" (Hassan et al., 2015, 32).

As a result of the arrival of Syrians in increasing numbers and the proliferation of demands on public services at different levels of government, the Directorate General of Migration Management of the Republic of Turkey's Ministry of the Interior issued the Temporary Protection Regulation (TPR) in 2014. The TPR identifies Syrians as Syrians under Temporary Protection (SuTP), granting them a legal status conditional upon registration with the legal authorities, and providing an identification card that allows access to and use of a range of public services. By the time the TPR was in full force, close to 90 per cent of the Syrians were in different urban centres. In addition to the access to translation services, education and labour markets, the TPR provides the right to access health services for Syrians under Temporary Protection with Article 20 on health checks, which reads:

(1) Emergency health services shall be provided as a priority to foreigners, who arrived at the referral centres and are determined to have emergency health needs. (2) Foreigners under this Regulation, who are considered to potentially pose a threat to public health, shall undergo health checks in 
accordance with procedures and principles to be determined by the Ministry of Health and necessary measures shall be taken when considered necessary.

Temporary Protection Regulation, 2014, n.p.

The Ministry of Health $(\mathrm{MoH})$ in Turkey oversees mental health services. The “organization, duties, mandate and responsibilities" of the $\mathrm{MoH}$ include planning for and establishment of both private and public healthcare institutions (Statutory Decree 663) ${ }^{1}$ that will also attend to mental health (Strategic Plan 2013-2017). ${ }^{2}$ Moreover, the rights of those with mental health problems are ensured through several articles in the Constitution in which Article 61 safeguards their "protection and social integration" (Munir, Ergene, Dağ, Erol, \& Aker, 2006). Restructuring of the $\mathrm{MoH}$ through the Health Transformation Programme had several consequences for the management of health services in Turkey and the responsibilities concerning "health system policy development, planning, supervision of implementation, monitoring and evaluation" (World Health Organization [WHO], 2013, n.p.). The $\mathrm{MoH}$ governs emergency management in terms of alleviating the harm caused by disasters on the health of the population. The $\mathrm{MoH}$ is also in charge of introducing psychosocial support services in emergencies. The $\mathrm{MoH}$ organises preventative services as well as health services development and research. Each of the 81 provinces in Turkey has a Public Health Director and a Deputy Health Director. Mental Health Programme Units are one type of health service governed separately. The $\mathrm{MoH}$ is the body mainly responsible for the provision of mental health services. Community Mental Health Centres stand as key institutions for providing counselling, training services, home visits and outpatient services. ${ }^{3}$ As many scholars have noted, in all countries receiving refugees, national healthcare systems have been challenged, although the Turkish healthcare system has coped with the influx much better than others in the Middle East (Hunter, 2016).

Refugees, especially the SuTP, are able to access secondary and tertiary health services as citizens do with a fee (Regional Refugee \& Resilience Plan [3RP], 2016-2017). The mental health and wellbeing of refugees are attended to by AFAD, NGOs and international organisations (IOs) in Turkey alongside the $\mathrm{MoH}$. Additionally, local NGOs such as the Association for Solidarity with Asylum Seekers and Migrants (ASAM) provide psychosocial support services for refugees (Ozcurumez \& Yildirım, 2017). However, there are questions around whether the services provided lead to recovery or whether they help prevent further trauma in post-emergency situations (Jefee-Bahloul, Barkil-Oteo, Pless-Mulloli, \& Fouad, 2015).

Although the legal barrier to accessing health services including mental health services is removed as a result of the TPR, the institutional barriers which also exist in non-emergency situations remain as they are in all healthcare settings, as evidenced by studies on health services access in refugee settlement countries (Ozcurumez \& Wylie, 2012). There is a lack of health service providers in general, and mental health service providers in particular, which could assist the SuTP in Arabic. Moreover, cultural stigma prevails over accessing MHPSS for the Syrian 
population as it does for other populations in different settings, which is similar to findings for healthcare delivery in diverse settings (Ozcurumez \& Wylie, 2012). However, there are serious gaps concerning the wellbeing needs of women and children who have been subject to exploitation, early marriages and different forms of gender-based violence for which there are extensive efforts by public institutions, NGOs and IOs. While scholars report a decrease in stigma attached to receiving mental health services, lack of financial resources remains as a consistent barrier for refugees to access services in Turkey (Hassan et al., 2015; 3RP, 2016-2017) in addition to language barriers between the SuTP and healthcare providers.

\section{Actors, institutions and the scale barrier}

The main challenge in accessing MHPSS is the language barrier between the healthcare providers and those seeking services. There is a serious lack of healthcare providers who can speak Arabic. Moreover, the scale challenge, which is providing MHPSS to more than 3 million Syrians with diverse needs as well as other refugees, is an unprecedented one from a perspective of a middle-income country sustaining services for such a large population for 7 years.

As the EU-Turkey Joint Action Plan on the EU-Turkey Statement (2015) progressed towards provision of financial resources for strengthening of health services, several projects began. One of these is the 'Sihhat' project (translates as 'wellbeing').This project aims to establish 178 Migrant Health Centres through which 790 doctors, 790 nurses, 84 health technicians, 300 support personnel, 960 patient guides and 26 drivers would be employed, as well as mobile health units and secondary healthcare institutions. Among many specific aims, the project aims to strengthen the secondary step health institutions in 28 provinces where the Syrians are concentrated, to provide for 26 additional mobile health units, five cancer screening units, and ten mental health units in the cities with a high concentration of Syrians. The project also includes training for 2520 healthcare personnel who work with Syrians on a range of themes to increase human resource capacity for healthcare services (Sihhat Project, n.d.). The $\mathrm{MoH}$ and WHO collaborate with NGOs such as ASAM to complement their extensive efforts to improve health services delivery.

Recognising that stigmatisation by their own community might prevent SuTP from accessing services, the International Organisation for Migration (IOM) has designed support programmes for men as well, such as the booklet entitled Self-Help Booklet for Men Facing Crisis and Displacement (IOM, 2014). The booklet addresses the psychological stress that may be related to job loss in addition to the trauma caused by fleeing conflict. The booklet highlights how in crisis the way that individuals deal with stress matters for their wellbeing and provides various suggestions for dealing with stress and anger and performing fathering roles for children.

Several efforts also aim to address the needs of children and adolescents. The United Nations Children's Fund (UNICEF) is among the agencies that support regular, structured psychosocial support for more than 130,000 refugee children, identify and refer thousands of children to specialised child protection services, 
strengthen and expand community-centred gender-based violence initiatives for tens of thousands of children and support training and capacity for thousands of frontline and child workers to improve overall child protection (UNICEF, 2017). While tens of thousands who have been reached might signal a beacon of hope for MHPSS access, it is critical to consider that around 45 per cent of the SuTP in Turkey are children, close to 1.5 million. The European Union (EU) has placed special emphasis on quality child protection and PSS as well as intervention as a means to improve the conditions for both. Therefore, the EUTF-MADAD fund emphasises activities for child protection as central to the specific country objective for Turkey, "to improve psychosocial well-being, emotional stability and the protective environment for refugee and vulnerable Turkish children" (Action Document for EU Trust Fund, 2017, 10). Therefore, the urgently needed international and national commitment is embedded in international deals as well as marked in budgets. However, the projects that aim to realise these objectives only began in 2017, and as of the writing of this chapter, are at their very incipient stages.

\section{Conclusions}

Turkey's healthcare system as a whole has been coping with the demands coming from millions of SuTP over the past 7 years. While identifying the SuTP as 'temporary' in legal terms, Turkey has covered the SuTP with the universal mode of delivery in health services in general, including MHPSS. Therefore, the common perception of the temporariness of this group has slowed down the overall approach for initiating and pursuing policies for social cohesion. The perception has not led to major cuts in service delivery, particularly health services delivery. In addition to their basic health needs, perinatal health, and treatment for communicable and non-communicable diseases, these individuals in general need MHPSS. However, as has been the case with most of the countries receiving mass numbers of refugees, Turkey has also coped with the MHPSS needs of these populations in accordance with its available legal, administrative, institutional and human resources.

The overall framework for addressing the needs of these populations corresponded with a transformation period in the mental health services in the country. Nonetheless, significant challenges continue: language barriers, shortage of trained personnel, shortage of facilities to address the special needs of refugee populations, lack of long-term projects, shortage and lack of monitoring mechanisms for identifying best practices, shortage of accessible and available resilience mechanisms for individuals, discriminatory practices, waning public support and heightened social tensions. However, once an international treatybased framework such as the Global Compact for Refugees is in place and a more comprehensive approach to receiving and hosting refugee populations is established, Turkey's experience of advancing a model that sustained an emergency response by involving multiple actors at multiple levels on a need basis is likely to stand out as a present-day best practice for the incorporation of MHPSS to an emerging refugee regime. 


\section{Notes}

1 www.mevzuat.gov.tr/MevzuatMetin/4.5.663.pdf [Retrieved on 1 April 2018].

2 Ministry of Health Strategic Plan 2013-2017: http://dosyasb.saglik.gov.tr/Eklenti/ 9843,saglik-bakaligi-stratejik-plan--2013-2017pdf.pdf [Retrieved on 30 July 2018].

3 Toplum Ruh Sağlığ Merkezleri Hakkında Yönerge (Regulation on Community Mental Health Centres, 16/02/2011, 7634 Approval): www.saglik.gov.tr/TR,11269/toplumruh-sagligi-merkezleri-hakkinda-yonerge.html [Retrieved on 8 April 2018].

\section{References}

Action Document for EU Trust Fund to Be Used for the Decisions of the Operational Board. (2017). Retrieved on 21 February 2018 from https://ec.europa.eu/neighbourhoodenlargement/sites/near/files/eutf_madad_action_document_for_regional_education_ 30062017.pdf

Convention Relating to the Status of Refugees, 28 July 1951, United Nations, Treaty Series, vol. 189, p. 137. Retrieved on 13 February 2018 from www.unhcr.org/ 3b66c2aa10

Diaz, J. O. P. (2008). Integrating psychosocial programs in multisector responses to international disasters. American Psychologist, 63(8), 820-827.

Global Compact on Refugees, Final Draft. (2018). Retrieved on 30 July 2018 from www. unhcr.org/5b3295167

Hassan, G., Kirmayer, L. J., Mekki-Berrada, A., Quosh, C., el Chammay, R., Deville-Stoetzel, J. B., [...] Ventevogel, P. (2015). Culture, Context and the Mental Health and Psychosocial Wellbeing of Syrians: A Review for Mental Health and Psychosocial Support Staff Working with Syrians Affected by Armed Conflict. Geneva: UNHCR.

Hassan, G., Ventevogel, P., Jefee-Bahloul, H., Barkil-Oteo, A., \& Kirmayer, L. J. (2016). Mental health and psychosocial wellbeing of Syrians affected by armed conflict. Epidemiology and Psychiatric Sciences, 25, 129-141.

Hunter, P. (2016). The refugee crisis challenges national health care systems. EMBO Reports, 17(4), 492-495.

IASC Reference Group on Mental Health and Psychological Support in Emergency Settings. (2010). Mental Health and Psychological Support in Humanitarian Emergencies: What Should Humanitarian Actors Know? Geneva. Retrieved on 21 February 2018 from www. who.int/mental_health/emergencies/what_humanitarian_health_actors_should_know. pdf

International Organisation for Migration. (2014). Self-Help Booklet for Men Facing Crisis and Displacement. Retrieved on 21 February 2018 from https://publications.iom.int/books/ self-help-booklet-men-facing-crisis-and-displacement-0

Jefee-Bahloul, H., Barkil-Oteo, A., Pless-Mulloli, T., \& Fouad, M. F. (2015). Mental health in the Syrian crisis: Beyond imediate relief. The Lancet, 386(10003), 1531.

Joint Action Plan on the Implementation of the EU-Turkey Statement. (2015). Retrieved on 30 July 2018 from https://ec.europa.eu/commission/sites/beta-political/files/december 2016-action-plan-migration-crisis-management_en.pdf

Ministry of Health Strategic Plan 2013-2017. (Stratejik Plan 2013-2017). Retrieved on 30 July 2018 from http://dosyasb.saglik.gov.tr/Eklenti/9843,saglik-bakaligi-stratejik-plan-2013-2017pdf.pdf

Munir, K., Ergene, T., Dağ, I., Erol N., \& Aker,T. (Eds.). (2006). National Mental Health Policy. Ankara, Turkey: Ministry of Health Türkiye. 
Ozcurumez, S., \& Wylie, L. (2012). Strategies for Change among Institutional and Societal Actors. In C. Falge, C. Ruzza \& O. Schmidtke (Eds.), Migrants and Health: Political and Institutional Responses to Cultural Diversity in Health Systems (pp. 139-176). Farnham, UK: Ashgate Publishing Ltd.

Ozcurumez, S., \& Yıldırım, D. (2017). Syrians under Temporary Protection, Health Services and NGOs in Turkey: Association for Solidarity with Asylum Seekers and Migrants and Turkish Medical Doctors' Association. In S. Greer, M.Wismar, G. Pastorino \& M. Kosinska (Eds.), Civil Society and Health: Contributions and Potential (pp. 105-124). Copenhagen: European Observatory on Health Systems and Policies.

Protocol Relating to the Status of Refugees, 31 January 1967, United Nations, Treaty Series, vol. 606, p. 267. Retrieved on 20 January 2018 from https://treaties.un.org/doc/ Publication/UNTS/Volume\%201125/volume-1125-I-17512-English.pdf

Regulation No. 1994/6169. (1994). On the Procedures and Principles Related to Possible Population Movements and Aliens Arriving in Turkey either as Individuals or in Groups Wishing to Seek Asylum either from Turkey or Requesting Residence Permission in Order to Seek Asylum from Another Country. Retrieved on 30 July 2018 from www. refworld.org/docid/49746cc62.html

Sihhat Project. (n.d.). Retrieved on 21 February 2018 from www.sihhatproject.org/projefaaliyetleri_0-657

Temporary Protection Regulation. (2014). Retrieved on 21 February 2018 from www.goc. gov.tr/files/_dokuman28.pdf

3RP Regional Refugee \& Resilience Plan 2016-2017. (n.d.). Retrieved on 30 July 2018 from http://reporting.unhcr.org/node/12589

3RP Regional Refugee \& Resilience Response Overview. (2018-2019). Retrieved on 30 July 2018 from www.3rpsyriacrisis.org/

Türk, V. (2016). A Minor Miracle: A New Global Compact on Refugees. Retrieved on 21 February 2018 from www.unhcr.org/admin/dipstatements/583404887/minor-miraclenew-global-compact-refugees.html

United Nations. (n.d.a). New York Declaration for Refugees and Migrants. Retrieved on 21 February 2018 from www.unhcr.org/new-york-declaration-for-refugees-and-migrants. html

United Nations. (n.d.b). Turkey: Law No. 6458 of 2013 on Foreigners and International Protection. Retrieved on 21 February from www.refworld.org/docid/5167fbb20. html

UNICEF. (2017). Preventing a 'Lost Generation' in Turkey. Retrieved on 30 July 2018 from www.unicef.org.tr/files/bilgimerkezi/doc/UNICEF\%20TCO_Fact\%20Sheet_01.2017. pdf

Wessells, M. G. (2009). Do no harm: Toward contextually appropriate psychosocial support in international emergencies. American Psychologist, 64(8), 842-854.

Wessells, M., \& van Ommeren, M. (2008). Developing inter-agency guidelines on mental health and psychosocial support in emergency settings. Intervention, 6(3), 199-218.

Wietse, A. T., Patel, V., Tomlinson, M., Baingana, F., Galapatti, A., Silove, D., [...] PanterBrick, C. (2012). Relevance or excellence? Setting research priorities for mental health and psychosocial support in humanitarian settings. Harvard Review of Psychiatry, 20(1), 25-36.

World Health Organization. (2013). Country Cooperation Strategy at a Glance:Turkey. Available at www.who.int/countryfocus/cooperation_strategy/ccsbrief_tur_en.pdf 